\title{
Globalización, conectividad interespacial y articulación territorial de los puertos mexicanos
}

Carlos Martner-Peyrelongue. Instituto Mexicano de Transporte, Querétaro, México.

RESUMEN | Ante el crecimiento exponencial de la conectividad interespacial y la movilidad en la actual fase de globalización de la economía-mundo, se analizan las implicaciones geográficas y territoriales de los nuevos paradigmas del transporte internacional, que han impulsado la formación de una red global de puertos y transporte multimodal. Luego se aportan criterios de análisis para establecer los desafíos de conectividad logística, modal y territorial que tienen los puertos mexicanos en la actualidad; y se reflexiona sobre el papel fundamental que desempeñan los actores en la intensificación de la conectividad a diferentes escalas, articuladas a través de redes y corredores multimodales. Finalmente, se reflexiona sobre la posición que mantienen los principales puertos del país dentro de la red global; sobre su potencial de desarrollo como hubs regionales; y sobre la problemática de la articulación entre fragmentos territoriales distantes y dispersos, pero a la vez fuertemente integrados en procesos de producción, distribución y circulación globalizados.

PALABRas ClaVE | redes, globalización, integración territorial.

ABSTRACT | Faced with the exponential growth of the inter-spatial connectivity and the mobility in the current globalization phase of the world economy, the geographic and territorial implications of the new international transport paradigms that have promoted the formation of a global network of ports and multimodal transport are analyzed. Additionally, analysis criteria are provided to establish the logistic, modal and territorial connectivity challenges that Mexican ports face today, adding some reflections on the fundamental role played by the actors in the intensification of the inter-spatial connectivity at different scales, which articulate through multimodal networks and corridors. Finally, a reflection is conducted on the position of the main ports of the country at the global network, their potential of development as regional hubs and on the issues posed by the articulation between distant and dispersed territorial fragments, but at once strongly integrated into processes of a globalized production, distribution and circulation.

KEYWORDs | networks, globalization, territorial integration. 


\section{Introducción}

La manera en que los puertos se articulan con el territorio ha sido siempre un aspecto crítico para su evolución y desarrollo. Se trata de un vínculo complejo, mediado y determinado tanto por el desarrollo tecnológico y organizativo del transporte, como por los imperativos del modelo económico dominante en un periodo histórico determinado. Así es como, en la actual fase de globalización de la economía-mundo, se están modificando los paradigmas sobre los cuales se sostuvieron los estudios portuarios realizados desde diversas perspectivas disciplinarias, tales como la geografía, la economía y la administración, entre otras. En particular, pierden fuerza explicativa los enfoques funcionalistas dentro de las ciencias sociales y la geografía, que ubican la unidad de análisis en los propios espacios portuarios y, por lo tanto, tienden a estudiarlos como entidades en sí mismas donde se desarrollan actividades comerciales, de servicios y de traslado de la mercancía.

En contraparte, cobran mayor notoriedad los enfoques sistémicos que ubican a los puertos en una posición nueva dentro de las cadenas de circulación física de las mercancías. En efecto, ahora los puertos son visualizados como nodos intermedios dentro de redes de logística y transporte multimodal que permiten articular cadenas de producción-distribución globalizadas, cuyos bienes son movilizados sin ruptura y de puerta a puerta por contenedores con estándares que se adaptan a los distintos modos de transporte y pueden desplegarse sobre localizaciones múltiples en diversos continentes, a través de servicios multimodales.

Los puertos principales, en tanto concebidos como nodos peculiares, son llamados concentradores o pivotes por los especialistas de la Comisión Económica para América Latina y el Caribe (Cepal) (Burkhalter, 1999; Hoffmann, 2000); o hubs, por los especialistas anglosajones (Fossey, 1997; O’Kelly, 1998). Tales denominaciones obedecen a su capacidad de concentrar, procesar y distribuir flujos internacionales de mercancías e información correspondientes a cadenas de valor ampliamente fragmentadas en el tiempo y en el espacio. Desde tal perspectiva, la problemática de la conectividad modal y territorial asume un papel central en la sobrevivencia y en la viabilidad de largo plazo de estas entidades portuarias de la globalización.

Dado este marco, el presente trabajo tiene por objetivo analizar la conectividad territorial, multimodal y logística de los principales puertos de contenedores de México, un proceso desplegado en un contexto de creciente competencia y reestructuración de las redes globales y continentales de transporte, que está permitiendo la emergencia de un espacio de flujos (Castells, 2006) y/o territorio de redes (Veltz, 2014) propio de la globalización. Tales flujos o redes instauran nuevas formas de ordenación del territorio, caracterizadas por vínculos entre fragmentos territoriales distantes y dispersos, pero a la vez fuertemente integrados en sus procesos productivos, debido al enorme desarrollo de la logística de aprovisionamiento y distribución.

La aceleración de la conectividad territorial, modal y logística es uno de los temas pendientes de la reestructuración portuaria en México, cuyo actual perfil de desempeño parece estar afectando la competitividad de los puertos nacionales. 
Esta problemática, sin embargo, no puede ser cabalmente comprendida ubicando la unidad de análisis en el ámbito local o nacional. En consecuencia, el presente trabajo parte del reconocimiento de que solo es viable un enfoque de tipo estructural-sistémico (Yocelevsky, 1999), donde la unidad de análisis se ubica en las determinaciones del ámbito global; es decir, en la reconfiguración del sistema mundial capitalista basada en el predominio de la circulación y lo financiero sobre lo productivo. Es este el orden que -según Brenner (2013) y De Mattos (2016), entre otros- ha propiciado un crecimiento exponencial de la conectividad y la movilidad, permitiendo articular una red urbana global estructurada por flujos tangibles (extracción de recursos y flujos de mercancías) e intangibles (flujos de información y de capitales).

A partir de tal enfoque, el trabajo se estructura, aparte de la presente introducción, en cuatro secciones y unas reflexiones finales. En primer lugar, se plantean algunas consideraciones sobre los sistemas de transporte, los puertos y la logística relevantes para el análisis geográfico actual. En segundo lugar, se analizan los nuevos paradigmas del transporte internacional que han impulsado la formación de una red global de puertos de contenedores y transporte multimodal, principalmente bajo el llamado modelo de distribución hub and spoke (Martner, 2010). En tercer lugar, se aportan criterios de análisis para establecer los desafíos de conectividad logística, modal y territorial que enfrentan los puertos mexicanos de contenedores, si quieren constituirse en concentradores regionales dentro de la red global de transporte multimodal en formación. Posteriormente, se reflexiona sobre el papel fundamental que desempeñan los actores en la intensificación de la conectividad interespacial en diferentes escalas, articuladas a través de la formación de redes y corredores multimodales. Finalmente, se reflexiona sobre la posición de los principales puertos del país en la red global, sobre su potencial de desarrollo como concentradores o hubs regionales, y sobre los desafíos pendientes en torno a la problemática de la articulación logística y territorial.

\section{Intensificación de la conectividad de los sistemas de transporte: nuevas consideraciones para la geografía}

\section{Fragmentación de la producción e importancia creciente de la circulación}

Desde la perspectiva tecnológica, operativa y organizacional, una de las características fundamentales de la globalización ha sido la posibilidad de fragmentar los procesos productivos, permitiendo que cada fase de la fabricación de un bien se realice en territorios, regiones, países e incluso continentes distintos, en función

"El modelo de distribución Hub-and-Spoke es un sistema de conexiones que permite reducir el número de rutas para comunicar los aeropuertos entre sí. Consiste en concentrar el tráfico en determinados aeropuertos de gran capacidad o Hubs que se encargan de enlazar los de menor capacidad o importancia Spokes". Universitát Politècnica de València, Ingeniería aeroportuaria, "Hub-and-Spoke", https://ingenieriaaeroportuaria.blogs.upv.es/2013/06/28/hub-and-spoke/. Ahora bien, aunque el modelo en cuestión se desarrolló inicialmente en el transporte aéreo, posteriormente fue adoptado por el transporte marítimo y los puertos, así como por las terminales multimodales terrestres. 
de las ventajas competitivas que cada lugar proporciona. Este escenario provocó un desdoblamiento de la producción -o, si se quiere, del proceso de producción inmediata- sobre el territorio. Así, si la producción que en el periodo previo a la globalización estaba, en buena medida, confinada en un solo lugar (la fábrica, la usina), ahora se ha desdoblado sobre vastos espacios dispersos, donde se realiza cada una de las fases mencionadas. De allí que, hoy en día, la necesidad de mover flujos crecientes de bienes intermedios, es decir, en proceso de fabricación, implique una intensificación inédita de la movilidad de las mercancías, una aceleración de la circulación física de los flujos materiales (y también inmateriales).

Desde la perspectiva de la geografía (económica, humana, y de los transportes), los cambios son inconmensurables. Implican alteraciones notables en la movilidad, en la conectividad de los sistemas de transporte, en los territorios. Significan que ahora es necesario realizar un gran número de traslados en el territorio para integrar el producto final. En otras palabras, requieren más transporte. Desde tal perspectiva, se considera que la intensificación de la conectividad y de la movilidad es una característica consustancial a la globalización. Y, desde luego, la logística desempeña un papel central en todo este proceso: en el control y la dosificación de los flujos de mercancías e información; en la formación y consolidación de los embarques; en el manejo de los inventarios; en el diseño de las cadenas de suministro, de las rutas, de los nodos de distribución y de los modos de transporte utilizados, entre otros aspectos técnicos y normativos.

\section{Territorio de redes y conectividad espacial fragmentada}

El modelo actual de desregulación, privatización y apertura comercial, aunado a la reciente innovación tecnológica, ha propiciado la constitución de extensas redes que permiten acercar fragmentos o nodos territoriales selectos dentro del proceso de conexión de la producción a escala global. Así, nunca antes en la historia se ha minimizado o trivializado tanto la importancia de la distancia física entre los lugares. Hay una suerte de anulación de la distancia por el tiempo, que permite que fragmentos territoriales distantes vinculados por redes globales de producción y circulación se encuentren más integrados entre sí que con sus regiones contiguas.

Las relaciones de proximidad, de cohesión geográfica y cultural entre un centro o polo y sus áreas contiguas, ahora tienden a desestructurarse por la emergencia de lo que Veltz $(1999,2014)$ ha llamado "territorio de redes", donde predominan las relaciones entre nodos fragmentados y territorialmente discontinuos que, sin embargo, se conectan o articulan, aun a largas distancias, con el apoyo de las recientes innovaciones tecnológicas, principalmente en las comunicaciones y los transportes.

Tal como señala Vetz (1999),

... las imágenes espontáneamente asociadas con la noción de territorio de redes hacen referencia, como es lógico, a las redes de comunicación y, en particular, a los efectos ocasionados por los transportes a gran velocidad (...). Estas redes crean a la vez nuevos enlaces y efectos "túnel" en las zonas atravesadas, pero sin parada -lo que el término inglés channelization expresa tan bien-, muy perturbadores desde el punto de vista de la continuidad territorial. (pp. 60-61) 
En este planteamiento destacan dos elementos relevantes. En primer lugar, el efecto túnel indica que hay una serie de territorios o espacios intermedios sobre los que pueden pasar tramos de la red pero que, básicamente, están desconectados o excluidos. Y es que la globalización de los procesos productivos y sociales "no requiere del control del espacio continuo, es decir, de la totalidad del espacio para operar. Logra su expresión en puntos selectos - place o 'lugares' à la Giddens-" (Hiernaux, 1993, p. 9).

Ciertamente no todo es red: "vastas áreas escapan a ese diseño reticular, (...), son magmas o zonas de baja intensidad” (Santos, 2000, p. 227). En este sentido, el territorio de redes en el sistema-mundo capitalista (Wallerstein, 1996) es parcial y selectivo, pero sus efectos se dejan sentir de manera generalizada. Por ejemplo, la mayor parte de los puertos del Pacífico mexicano, que en el periodo previo cumplían una función regional, enfrentan dificultades para articularse a este espacio de redes y flujos de la globalización, lo cual ha propiciado prolongados procesos de estancamiento y declinación.

En segundo lugar, la red es económica, pero es también social y política, por los flujos de capital y de mercancías, por los agentes que operan en ellas, por los mensajes y las órdenes. "Sin esto, y a despecho de la materialidad con que se impone a nuestros sentidos, la red es, en verdad, una mera abstracción” (Santos, 2000, p. 222).

En este mismo tenor, Santos continúa refiriéndose a un espacio reticular que preside una nueva forma de sociabilidad a distancia. Ese nuevo discurso del espacio de la conectividad y las redes "es el lenguaje de las normas y órdenes que actores lejanos hacen repercutir instantánea e imperativamente sobre otros lugares distantes. Tales redes constituyen los más eficaces transmisores del proceso de globalización al que asistimos" (p. 225).

El propio Brenner (2013), en su tesis sobre la urbanización planetaria, resalta el papel crucial de las redes y la conectividad interespacial en este proceso. En efecto, señala, "dentro de este campo de desarrollo urbano extendido y cada vez más universal, las aglomeraciones se forman, expanden, contraen y transforman de manera continua, pero siempre a través de densas redes de relaciones con otros lugares, territorios y escalas" (p. 61).

La intención última de las redes y sus nodos es activar flujos de diversa índole (capital-dinero, mercancías, órdenes de producción, valores, símbolos) que den continuidad al proceso de acumulación de capital y a la reproducción de la economía-mundo capitalista. Este es el sentido en el que Castells (2006) habla de la creación de un espacio de flujos que se superpone a y desestructura los vínculos territoriales previos, fundados en la proximidad y en rasgos comunes de identidad.

Entonces, la necesidad de crear fluidez y acelerar la circulación se convierte en un problema central del sistema en esta fase de globalización. Se establecen lugares y se crean objetos (como puertos, aeropuertos, terminales intermodales, autopistas, oleoductos, etcétera) para favorecer la fluidez. En la actualidad, "estos objetos transmiten valor a las actividades que los utilizan. En este caso podemos decir que circulan. Es como si ellos también fuesen flujos" (Santos, 2000, p. 232). 
Fluidez, redes y circulación física en el centro del debate de la geografía de los transportes

La intensificación de los flujos y el mayor protagonismo de la circulación modifican los enfoques teóricos previos. En especial, aquel que se refiere a la dicotomía conceptual entre la producción inmediata y la circulación, que tanto la teoría neoclásica como el estructuralismo marxista consideraban categorías claramente diferenciadas y secuenciales. Como se señaló previamente, desde la perspectiva económica y territorial la producción inmediata estaba asociada a un espacio confinado (la fábrica), más que al control de los flujos entre nodos y redes de transformación de los materiales. A su vez, la circulación se concebía como un proceso externo que era determinado por la producción inmediata. En este contexto, los puertos, el transporte y la distribución física de las mercancías aparecían también como actividades externas que se sucedían al acto de producción.

No cabe duda de que, con la fragmentación de los procesos productivos a escala global, la circulación ha adquirido un protagonismo inédito. Los nuevos métodos de producir, basados en la logística -es decir, en el manejo estratégico de los flujos materiales e inmateriales, en la información de la demanda, en la eliminación de inventarios y en el aprovisionamiento justo a tiempo de insumos y materiales-, ubican el punto crítico del proceso en el control de los flujos, en las redes y, en última instancia, en la circulación. En términos de Coriat (1992), ahora lo comercial es lo que organiza y ordena los talleres, la lógica fordista es invertida: ya no se produce para vender, solo se produce lo que está vendido. En efecto, de acuerdo con este autor, las recientes innovaciones tecnológicas y organizativas dan lugar a un cambio fundamental en la búsqueda de la valorización. Ahora, "en vez de que la producción se haga en cadena desde el principio hasta el final del proceso, se hace desde el final hacia el principio del mismo. Esto significa que a partir de los pedidos hechos a la fábrica y, por lo tanto, de los productos efectivamente vendidos se programan las necesidades en unidades y en materiales" (p. 50). Desde esta perspectiva, pareciera reforzarse el papel de la circulación y ese imperativo de fluidez, propio del actual modelo de acumulación.

Algunos autores, con enfoques sistémicos sobre el análisis territorial y la geografía, proclaman sin ningún recato la supremacía de la esfera de la circulación. En la fase de globalización, dice Santos (2000), “como la circulación prevalece sobre la producción propiamente dicha, los flujos se han vuelto aún más importantes para la explicación de una determinada situación. La propia estructura geográfica se define por la circulación, ya que ésta, más numerosa, más densa, más extensa, ostenta el dominio de los cambios de valor en el espacio" (p. 227).

En el mismo sentido, posteriormente agrega:

... no basta con producir, sino que es indispensable poner la producción en movimiento. Entre los agentes económicos se impone distinguir, a partir de los volúmenes que producen o mueven, entre aquellos que crean flujos y aquellos que crean masas, es decir, que generan volúmenes, pero no tienen la fuerza de transformarlos en flujos. En realidad, ya no es la producción la que preside la circulación, sino que es ésta la que conforma la producción. (p. 232) 
De esta manera, el análisis de la producción no puede seguir siendo confinado a un lugar específico dentro de rígidas fronteras nacionales o regionales, menos aún cuando la formación de redes pone en duda la tajante dicotomía teórica entre producción y circulación. Se desdibujan fronteras conceptuales muy útiles cuando la unidad de análisis se ubica en espacios nacionales o regionales, pero poco efectivas para entender dinámicas recientes de la economía-mundo y de la transformación espacial global.

A través de las redes son transportados o desplazados objetos tangibles e intangibles que no han salido del proceso de producción inmediata. "La ampliación de los contextos posibilitada por la eficiencia de las redes hace también posible aquello que Marx previera en cuanto al uso del territorio: La disminución del ámbito de producción y (...) [simultáneamente] (...) la ampliación de su área” (Santos, 2000, p. 235). Es precisamente en este contexto donde la aceleración de la circulación es una condición sine qua non de la globalización. Por ello, la circulación está en el centro del debate.

En síntesis, hay que mover crecientes volúmenes de la producción fragmentada para poder integrarla; entonces hay que crear flujos o, si se quiere, fluidez y, para ello, se requieren redes. Redes cada vez más complejas y sofisticadas de transportes y comunicaciones, entre otras, para acelerar la movilidad de la mercancía y del capital. Tal como lo señaló en su momento Milton Santos (2000), "las redes constituyen los más eficaces transmisores del proceso de globalización al que asistimos" (p. 160). Son redes que conducen al desarrollo de nuevas formas de transporte integrado, con nodos clave de articulación de los flujos y de los territorios, como los puertos concentradores o hubs, por ejemplo.

La formación de las redes de transporte multimodal, con sus nodos clave (los hubs), solo fueron posibles por el cambio tecnológico y organizacional vinculado a la movilidad de la mercancía. En este sentido, los puertos de la globalización son visualizados como nodos intermedios dentro de las redes de logística y transporte multimodal, que permiten articular cadenas de producción-distribución globalizadas, desplegadas en localizaciones múltiples.

Desde la perspectiva aquí detallada, la contribución del presente trabajo para el análisis geográfico y urbano-regional reside en identificar y caracterizar los elementos constitutivos de una nueva forma de configuración del territorio, inspirada, en buena medida, en los conceptos de espacio de flujos (Castells, 2006), territorio de redes (Santos, 2000; Veltz, 2014) y conectividad interespacial (Brenner, 2013), aplicados al estudio de la conformación de extensas redes físicas y virtuales de transporte multimodal internacional y a sus nodos clave (los hubs), que están reduciendo eficazmente la rugosidad del espacio y las distancias (Dollfuss, 2007), cuestión fundamental en el desdoblamiento del proceso de mundialización capitalista. Así, desde la perspectiva de las redes multimodales globalizadas, el asunto es cómo entender el espacio cuando sus principales propiedades (la resistencia física a los cambios y ordenación según la distancia) se ven eclipsadas, cuando tiempo y espacio se vuelven más sincrónicos, debido a la eficiencia y eficacia de las redes.

Precisamente, es en el análisis de la formación de una red global de puertos y transporte multimodal donde se encuentran los elementos clave del proceso de conectividad interespacial y articulación territorial, modal y logística de los puertos mexicanos. 


\section{Conectividad interespacial, redes globales de transporte y puertos concentradores (bubs)}

\section{Hacia la progresiva conformación de una red global de puertos y transporte multimodal}

En el marco de la nueva era de conectividad interespacial propia de la globalización, el proceso de aceleración de la circulación y la creación de fluidez requirió de un nuevo modelo de organización del transporte, basado en el desarrollo de servicios multimodales puerta a puerta, que aseguraran la continuidad del suministro de bienes desde la planta en el país de origen, hasta la planta, centro de distribución o de venta en el país de destino. Fue en este contexto que emergió el modelo de distribución hub and spoke como elemento central para articular la fragmentación espacial propia de las cadenas productivas de la globalización. La construcción del concepto de hub (puerto concentrador o pivote, en espańol) proviene de los investigadores de países centrales dentro de la economía-mundo y, sin duda, refleja los cambios recientes que han sufrido en tecnología, en infraestructura y en organización los principales puertos de esos países durante las últimas décadas.

La proliferación del contenedor y el incipiente desarrollo del multimodalismo desde la segunda mitad de la década de los ochenta, así como el rápido incremento en tamaño de las embarcaciones, la concentración de carga en megaterminales, la multiplicación de los corredores intermodales y la formación de alianzas estratégicas de transporte de contenedores con cobertura global (megacarriers) desde los noventa en adelante, contribuyen a definir el concepto de hub como una plataforma logística concentradora de grandes volúmenes de carga e información. Procedentes de diversos continentes, carga e información son procesadas, organizadas y distribuidas hacia distintas regiones, por tierra o por mar, mediante una eficiente articulación modal y territorial de los sistemas de transporte que convergen en el nodo portuario.

Ahora bien, existen investigaciones previas donde se establecen diferentes categorías de hubs o puertos concentradores, dependiendo de sus características, dimensiones y localización en la geografía global de los flujos (figura 1). En términos generales y de manera esquemática, la red global se forma en un primer nivel por hubs globales, grandes concentradores y distribuidores de flujos de mercancías hacia distintos continentes, que normalmente se localizan entre el paralelo 30 y 60 del hemisferio norte, en los países desarrollados y algunos emergentes (China, principalmente) de los tres principales bloques económicos del sistema-mundo capitalista actual (Noreste asiático, Unión Europea y Norteamérica). En este denso eje esteoeste del hemisferio norte circulan los mayores flujos de carga intermodal, en los buques portacontenedores más grandes del mundo, cuya carga es transferida hacia redes terrestres de transporte multimodal o hacia buques medianos y pequeńos que distribuirán las mercancías hacia mercados menores. 


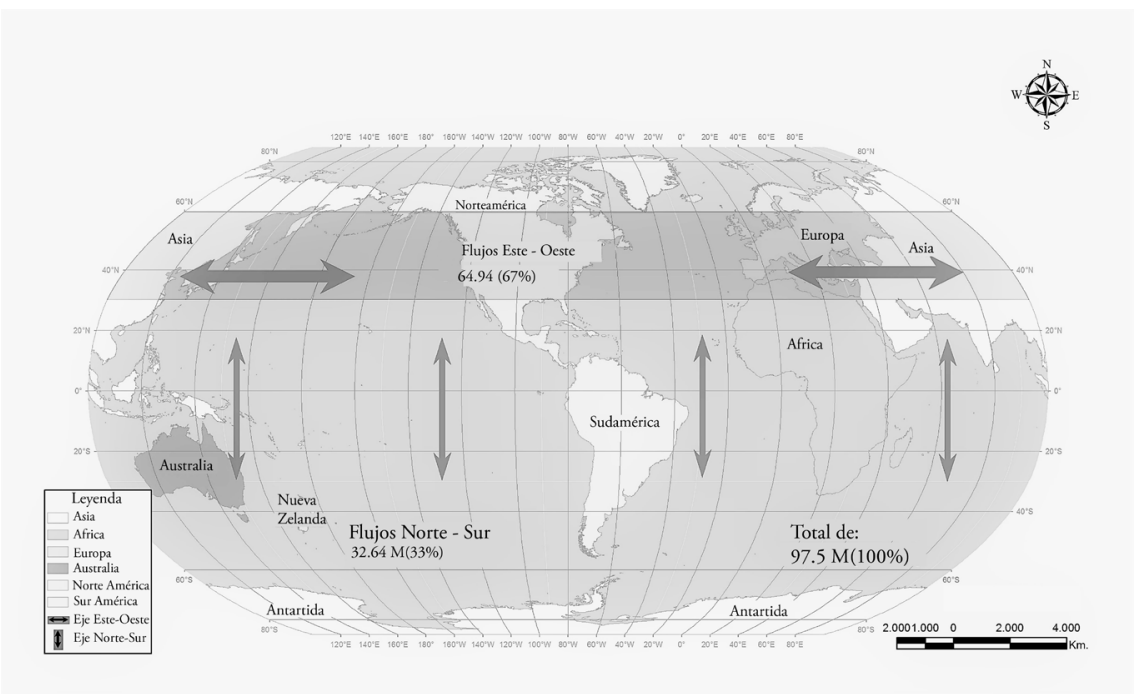

FIGURA I | Principales ejes de transporte multimodal internacional contenedorizado, 2013 (en TEU - Twenty-foot Equivalent Unit, unidad equivalente a un contenedor de 20 pies)

FUENTE: ELABORACIÓN PROPIA CON BASE EN DATOS DE CONTAINERISATION INTERNATIONAL, 20 I 4

En un segundo nivel aparecen los hubs regionales, cuya función es concentrar y distribuir flujos a nivel continental o subcontinental, procedentes de los hubs globales. Con la deslocalización reciente de fases de cadenas productivas globales hacia espacios periféricos e históricamente no centrales dentro de la economía mundo capitalista, la red global ha requerido una instancia intermedia entre el concentrador global y los puertos menores o alimentadores. Así, la mayoría de los hubs regionales se encuentran en las zonas de intersección de las rutas este-oeste con las rutas norte-sur (Martner, 2008).

En un tercer nivel se encuentran los puertos alimentadores, cuya densidad de flujos es menor, dada su localización en la geografía económica global; no obstante, tienen la función de suministrar bienes, en embarcaciones menores, a los hubs globales y regionales, donde serán transbordados a los grandes buques que circulan entre los corredores más densos de la red (figura 2). Finalmente, cabe mencionar que una gran cantidad de puertos, junto con los territorios donde están enclavados, parecen estar quedando excluidos de esta red de transporte internacional.

Ahora bien, en Latinoamérica el concepto de puerto hub o concentrador fue adoptado tal cual, sin análisis previo de sus características e implicaciones. Se asumió, sin más, como el nuevo paradigma del transporte marítimo y multimodal en la región; sin embargo, carece de un desarrollo conceptual que pueda dar cuenta, desde disciplinas como la geografía y economía del transporte, de las condiciones, límites y posibilidades de desarrollo de este tipo de complejo portuario en países periféricos (Martner, 2002). Así es como en los últimos años prácticamente no ha habido país latinoamericano sin proyecto de desarrollo de puerto hub (pivote o 
concentrador) en sus costas. En Sudamérica se habla insistentemente de desarrollar corredores bioceánicos atados a la creación de puertos pivotes (Hoffmann, 2000). En Centroamérica proliferan ideas y proyectos de hubs vinculados a los llamados Canales Secos, que unirían el litoral del Pacífico con el del Atlántico. En México se revive periódicamente el proyecto del corredor del istmo de Tehuantepec para conectar el Pacífico con el golfo en la franja más estrecha del país.

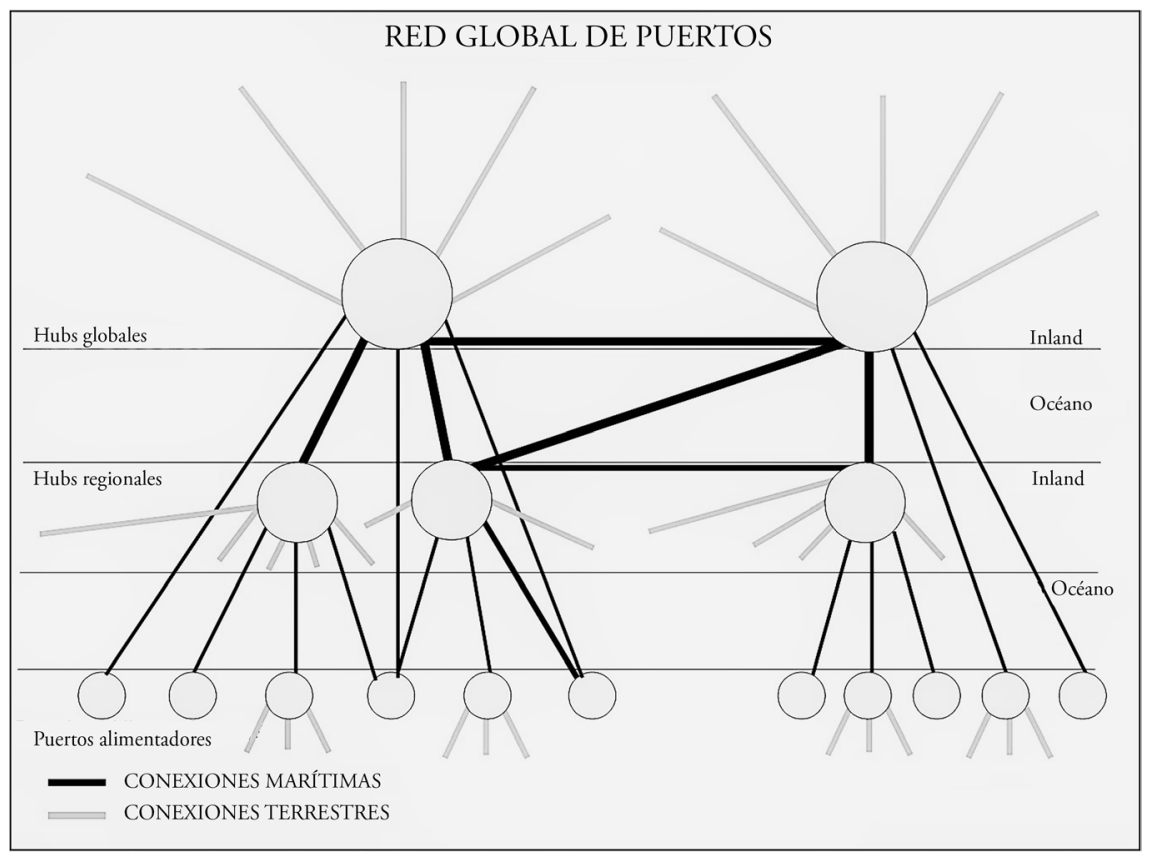

FIGURA 2 | Red global de puertos

FUENTE: ELABORACIÓN PROPIA

Aunque la potencialidad de cada proyecto es diferente, difícilmente las costas del continente podrán llenarse de hubs. Pretender en cada país uno o más puertos hub remite a enfoques dentro de las ciencias sociales que insisten en circunscribir la unidad de análisis a los límites del Estado-nación (Yocelevzky, 1999). En esa línea, neutralizan o diluyen las determinaciones propias del ámbito global o, si se quiere, del sistema-mundo (Braudel, 1985; Wallerstein, 1996), creando grandes expectativas con un débil sustento tanto conceptual como empírico. Por eso, en este trabajo se pretende avanzar hacia el desentrańamiento de las claves sistémicas que determinan la potencialidad y límites de los puertos mexicanos en el contexto internacional de transportación de mercancías.

Los puertos concentradores y las nuevas formas de articulación territorial La integración de un puerto hub o concentrador en la red global de transportes implica cambios territoriales sustanciales. El hinterland o zona de influencia 
territorial del puerto se amplía considerablemente, hasta alcanzar vínculos con múltiples fragmentos territoriales distantes en los cuales se desarrollan fases de la producción de diversa calificación y complejidad. La expansión de la red terrestre del puerto principal le permite, además, disputar y ganar el hinterland a puertos menores, afectando, de esta forma, el desarrollo de amplias zonas costeras.

En Latinoamérica, durante el periodo de sustitución de importaciones los puertos tenían una vinculación territorial limitada. En general, surtían de insumos y exportaban productos primarios o poco manufacturados desde el ámbito local y regional más cercano al puerto. Así, difícilmente otros puertos podrían disputar la zona de influencia territorial (hinterland) a un tercero, dada la deficiencia en los enlaces terrestres y la inexistencia de redes integradas de transporte (United Nations Conference on Trade and Development [UnCTAD], 1992).

A partir de la apertura comercial y de los procesos de reestructuración y de innovación en el transporte, se modificó la situación de los puertos y de su articulación territorial. En efecto, el desarrollo de infraestructura hacia puntos selectos del litoral y la creación de cadenas integradas de transporte en las que intervienen agentes sociales con presencia global, propician la desaparición de los hinterlands cautivos previos y modifican la importancia relativa de los puertos. Los puertos más dinámicos amplían su cobertura territorial e invaden la zona de influencia de puertos vecinos, otrora cautiva. Las mejoras en la accesibilidad territorial propician la conformación de hinterlands comunes a muchos puertos, cada vez más competidos por los actores portuarios y, en general, por los operadores de transporte multimodal.

En este contexto, la emergencia de hubs globales, con capacidad para desdoblar extensas redes sobre el territorio, con una elevada frecuencia de embarques, con la diversidad y volumen de los flujos actuales, tiende a propiciar cambios notables en la estructura territorial, que afectan no solo al puerto y su entorno urbanoregional inmediato, sino a amplios espacios y a la estructura de conexiones con regiones interiores. La conectividad interespacial así generada favorece o induce el desarrollo de nodos estratégicos de activación de flujos y corredores intermodales de transporte que difunden lo que Brenner (2013) llama la urbanización planetaria, apoyada en redes físicas y circuitos virtuales que aceleran la circulación de bienes tangibles e intangibles, como las mercancías, el capital dinero, las instrucciones tácticas y operativas, las órdenes de trabajo, etcétera.

Así, muchas actividades que requieren infraestructura especializada son inducidas por la presencia de un puerto concentrador. Tal es el caso de las plataformas logísticas de distribución y administración de inventarios, los centros de consolidación, las terminales de contenedores, los centros de información y comunicación, entre otros. La infraestructura de enlace también es motivo de cambios importantes, entre los cuales destacan la construcción de vías rápidas, autopistas, redes ferroviarias de doble estiba, terminales multimodales interiores y redes de fibra óptica para mejorar los canales de comunicación, entre otras. Asimismo, muchas actividades productivas se reorientan o ven inducida su localización por la presencia de las densas redes asociadas a los puertos hub o concentradores.

Por otra parte, los hubs regionales operan menores frecuencias y densidades de flujos que un concentrador global; sin embargo, no dejan de tener un importante 
papel como nodo articulador de territorios y redes de producción-circulación globales, al conectar eficientemente fragmentos territoriales de un país o área continental específica. En efecto, algunos hubs regionales, generalmente ubicados en lugares estratégicos de países periféricos, tienden a modificar cualitativamente los vínculos territoriales mediante la extensión de redes hacia una diversidad de regiones interiores, las mismas que en periodos previos no tenían enlaces adecuados con los puertos en cuestión.

En México, por ejemplo, algunos puertos mejoraron notablemente su conectividad interespacial mediante la construcción de autopistas, redes de fibra óptica, corredores de ferrocarril de doble estiba de contenedores, terminales multimodales, centros de distribución y zonas de actividades logísticas que, por su propia envergadura, implican modificaciones territoriales de determinados fragmentos espaciales y refuerzan los vínculos de puertos dinámicos (como Manzanillo, Lázaro Cárdenas, Veracruz y Altamira) con regiones interiores del centro y norte del país (tabla 1). Por el contrario, en los puertos menos dinámicos del sureste los enlaces terrestres con las regiones interiores han evolucionado lentamente, al registrar menor densidad de carreteras de altas especificaciones, servicios ferroviarios de baja frecuencia, así como la ausencia de servicios logísticos especializados.

\begin{tabular}{|l|c|c|}
\hline \multicolumn{1}{|c|}{ PRINCIPALES CORREDORES } & $\begin{array}{c}\text { KM } \\
\text { CARRETERAS }\end{array}$ & $\begin{array}{c}\text { KM VÍAS } \\
\text { FÉRREAS }\end{array}$ \\
\hline Manzanillo - Guadalajara - León - Ciudad de México & 820 & 960 \\
\hline Manzanillo - Aguascalientes - Monterrey & 1.086 & 1.380 \\
\hline Lázaro Cárdenas - Querétaro - Ciudad de México & 728 & 863 \\
\hline Lázaro Cárdenas - San Luis Potosí - Monterrey - Nuevo Laredo & 1.364 & 1.557 \\
\hline Veracruz - Puebla - Ciudad de México - Querétaro - Guadalajara & 900 & 1.031 \\
\hline Altamira - Ciudad Victoria - Monterrey - Saltillo - Torreón & 823 & 975 \\
\hline
\end{tabular}

TABLA I Conectividad de principales puertos mexicanos por carreteras de altas especificaciones y vías férreas (en kilómetros)

FUENTE: ELABORACIÓN PROPIA CON BASE EN DATOS DE LAS ADMINISTRACIONES PORTUARIAS Y DE LA SECRETARÍA DE COMUNICACIONES Y TRANSPORTES (SCT), MÉXICO

\section{Articulación logística y territorial de los puertos mexicanos}

En la nueva geografía de los flujos y redes de la globalización, es importante conocer la posición de los puertos mexicanos. Para ello hay que comenzar por dilucidar algunas interrogantes relevantes sobre el tema. En este sentido, cabe preguntarse: ¿Cómo se están articulando los puertos mexicanos a las redes globales? ¿Es factible impulsar actividades propias de puertos concentradores? ¿Existen las condiciones objetivas o potenciales? ¿O solo realizarán funciones de alimentación?

Para entender este posicionamiento, es necesario considerar aspectos clave de la geografía del transporte multimodal de carga. En este sentido, en la presente sección se ofrecen cuatro criterios de análisis que ayudan a entender los desafíos y posibilidades de los puertos nacionales ante el contexto global y regional de la actualidad. Espacialmente, dichos criterios vinculan tanto el foreland (esto es, las 
conexiones con el exterior) como el hinterland o zona de influencia territorial interior. Así, se parte de ubicar la posición de los puertos mexicanos ante los principales ejes o corredores de transporte multimodal internacional, hasta lograr identificar el ámbito espacial interior de donde obtienen la carga, la cobertura territorial que alcanzan, así como las características, cualidades y nivel de especialización de la infraestructura y los servicios logísticos e intermodales que ofrecen. Todo ello sin dejar de contrastar la información cualitativa con el repaso previo de la trayectoria de largo plazo de los puertos nacionales, mediante el análisis de series de tiempo que bien pueden incluir las últimas tres décadas, pero que lógicamente en este trabajo se presentan de manera resumida.

Criterio 1. Localización de los puertos mexicanos frente a los principales ejes multimodales internacionales

La ubicación geográfica de los puertos en función de los principales ejes de transporte marítimo e intermodal determina en buena parte las posibilidades de constituir concentradores regionales o globales dentro de la red. Hoffmann (2000) muestra claramente las dificultades para establecer puertos hub en la costa del Pacífico de Sudamérica; entre otras razones, por la lejanía con respecto a los principales ejes de transporte marítimo internacional.

Por lo general, los concentradores globales se encuentran ubicados en las rutas este-oeste del hemisferio norte. Esto tiene una relación directa con la presencia de los ejes más importantes y densos del comercio internacional, constituidos por las conexiones entre Europa, el noreste de Asia y Norteamérica. Los hubs regionales, en cambio, tienden a desarrollarse con mayor facilidad en las zonas donde se cruzan o conectan los principales ejes este-oeste con las rutas norte-sur. En el continente americano esto sucede sobre todo en la zona del canal de Panamá y el Caribe.

Aquí, la existencia del canal de Panamá y de dos concentradores regionales en ambas costas de tal vía acuática no es un hecho banal, pues propicia una extensión de las posibilidades de encuentro e interconexión entre los grandes buques que circulan en los corredores este-oeste y las embarcaciones menores que navegan en rutas norte-sur del continente americano (Martner, 2010).

En efecto, el hecho de que muchas embarcaciones grandes y medianas procedentes del Lejano Oriente tengan como mercado principal la costa atlántica de Estados Unidos, las obliga a bajar hasta Panamá para cruzar el canal interoceánico y dirigirse a su destino final. Lo propio sucede con los grandes buques procedentes de Europa que tienen como destino la costa del Pacífico de los Estados Unidos. Tal circunstancia da oportunidad para que se despliegue un extenso eje de intersección entre rutas principales (este-oeste) y rutas alimentadoras (sur-norte), el cual converge desde los litorales Pacífico y Atlántico de Estados Unidos hasta el canal de Panamá. Por ello no es extraño que, en la actualidad, los principales hubs regionales de transbordo de la región se localicen en los puertos panameños de Balboa (Pacífico) y Manzanillo (Atlántico), así como en los puertos caribeños de Kingston (Jamaica) y Freeport (Bahamas), mismos que se sitúan prácticamente sobre el citado eje.

En este contexto geográfico, cabe preguntarse, ¿dónde están los puertos mexicanos? Dada su ubicación geográfica, ¿existe la posibilidad de constituir hubs 
regionales o globales en las costas mexicanas? En primera instancia parecería que no se encuentran muy distantes de la zona de cruce o intersección de rutas. Principalmente, el Pacífico mexicano estaría ubicado sobre el eje de intersección constituido por Long Beach/Los Ángeles, California, y los hubs de transbordo del canal de Panamá. Por el contrario, el eje de intersección constituido por la costa atlántica de Panamá, los países-islas del Caribe y Florida alejan relativamente a los puertos mexicanos del Golfo, de la zona de conexión entre las rutas norte-sur y las rutas este-oeste (figura 3).

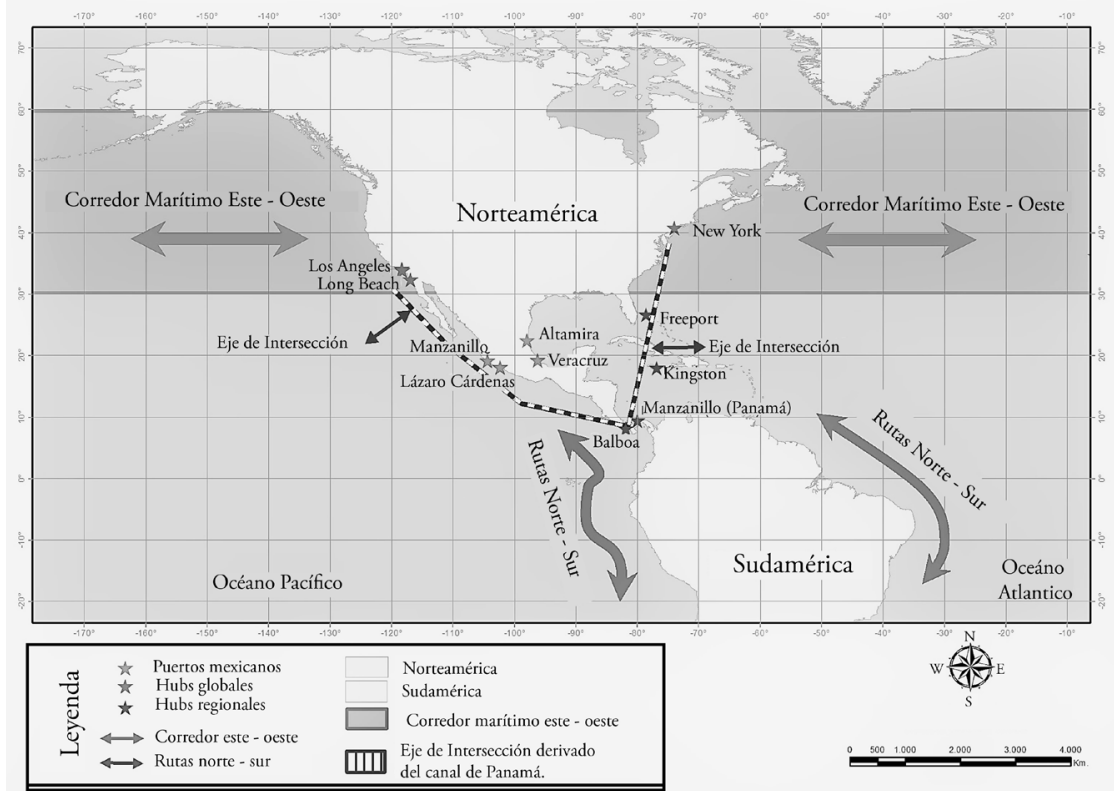

Figura 3 | Puertos mexicanos en el contexto de los principales ejes internacionales de transporte multimodal

FUENTE: ELABORACIÓN PROPIA

Así, los principales puertos del Pacífico mexicano, como Manzanillo y Lázaro Cárdenas, se encuentran en el eje de intersección señalado previamente y se caracterizan por haber ampliado notablemente su hinterland nacional, al concentrar cada vez más flujos de carga contenerizada generados o atraídos por múltiples regiones de producción y consumo del país. En tales circunstancias, eventualmente estarán en condiciones de aumentar el número de contenedores movidos, realizando funciones de transbordo entre las rutas norte-sur y las rutas este-oeste. En otras palabras, tendrían la posibilidad de escalar dentro de la red global de puertos hasta constituirse en hubs o concentradores regionales, que obtienen carga no solo de su hinterland ampliado, sino también de la interconexión marítima y las operaciones de transbordo. 
Al respecto, Zohil y Prijon (1999) señalan que las embarcaciones tienden a preferir los puertos para los cuales tienen carga local y aprovechan que ya están allí para realizar movimientos de transbordo. Cuanto menos desvío de la ruta principal implique la escala, más alta es la probabilidad de que el puerto sea elegido como hub de transbordo.

Los puertos de Manzanillo y Lázaro Cárdenas cumplen en buena medida con estos preceptos. Por una parte, obtienen crecientes volúmenes de carga contenerizada del hinterland; y, por otra, están muy cerca del eje de intersección entre rutas principales y alimentadoras. Por lo tanto, las ventajas comparativas están presentes; ahora falta que esa potencialidad se concretice mediante la acción de los actores públicos y privados vinculados a los puertos en cuestión. En este caso, se trata de establecer objetivos de planeación para posicionarse ante la fuerte competencia de otros puertos de la región que buscan concentrar carga y convertirse en hubs regionales, tanto en Centroamérica y el Caribe como en Norteamérica.

En el caso de los puertos del golfo de México, la fortaleza para avanzar dentro de la red global de puertos reside más que todo en las posibilidades de expansión de su hinterland. En este caso solo se estaría cumpliendo con la primera premisa de Zohil y Prijon (1999), pero no con la segunda, puesto que las principales rutas marítimas este-oeste no ingresan al golfo de México. En otras palabras, la mayor lejanía con respecto al eje de intersección de las rutas principales limita considerablemente la posibilidad de que los operadores marítimos y multimodales estén interesados en realizar actividades de transbordo en los puertos mexicanos del golfo. Así, el potencial de Veracruz y Altamira se encuentra básicamente en la posibilidad de expandir su zona de influencia territorial (hinterland) y captar mayores flujos de contenedores desde y hacia el interior del país. Ambos pueden aspirar a convertirse en concentradores o hubs de carga nacional en la medida en que fortalezcan sus conexiones intermodales.

Criterio 2. Dinamismo de la carga contenerizada en los puertos mexicanos Durante la década de los noventa, la creciente apertura comercial y la reestructuración portuaria en México dieron lugar a un cambio sustantivo en la evolución de los flujos de carga contenerizada, así como en la geografía portuaria nacional. El primer aspecto que destaca es el acelerado aumento de la carga general contenerizada en ambos litorales. El segundo es la concentración de estos flujos en pocos puertos nacionales. En 2017, dos puertos del Pacífico (Manzanillo y Lázaro Cárdenas) y dos puertos del golfo de México (Veracruz y Altamira) concentraron el 92,5\% de la carga contenerizada en los litorales nacionales (tabla 2). La tendencia hacia la concentración en pocos puertos "ganadores" (Ojeda, 2000) fue particularmente intensa durante la década de los noventa y mantuvo el mismo perfil en las siguientes dos décadas.

Si bien es cierto que la tasa de crecimiento anual por sí sola no arroja suficiente luz sobre la ubicación de los puertos en la red global, permite observar algunos indicios nada despreciables sobre el nivel de concentración que ha estado adquiriendo el sistema portuario nacional en las últimas dos décadas, así como obtener un primer esbozo sobre la potencialidad de los puertos hub en México. 


\begin{tabular}{|c|c|c|c|c|c|}
\hline $\begin{array}{c}\text { PUERTOS DEL } \\
\text { PACÍ́FICO }\end{array}$ & I988 (\%) & $2017(\%)$ & $\begin{array}{c}\text { PUERTOS DEL } \\
\text { GOLFO }\end{array}$ & I988 (\%) & $2017(\%)$ \\
\hline Ensenada & 0 & 5,3 & Altamira & 14,0 & 39,2 \\
\hline Guaymas & 21,6 & 0,4 & Tampico & 19,6 & 0 \\
\hline Mazatlán & 2,5 & 1,1 & Tuxpan & 17,3 & 0,4 \\
\hline Manzanillo & 27,0 & 65,5 & Veracruz & 44,4 & 54,5 \\
\hline Lázaro Cárdenas & 28,0 & 26,6 & Coatzacoalcos & 4,1 & 1,0 \\
\hline Acapulco & 2,2 & 0 & Progreso & 0,4 & 4,5 \\
\hline Salina Cruz & 18,5 & 0 & Resto & 0,2 & 0,4 \\
\hline Resto & 0,2 & 1,1 & & & \\
\hline Total & 100,0 & 100,0 & Total & 100,0 & 100,0 \\
\hline \multicolumn{3}{|c|}{ Movimiento en $1988=81,328$ TEU $^{*}$} & \multicolumn{3}{|c|}{ Movimiento en $1988=135,714 \mathrm{TEU}^{*}$} \\
\hline \multicolumn{3}{|c|}{ Movimiento en $2017=4,324,051 \mathrm{TEU}^{*}$} & \multicolumn{3}{|c|}{ Movimiento en $2017=2,051,287$ TEU $^{*}$} \\
\hline
\end{tabular}

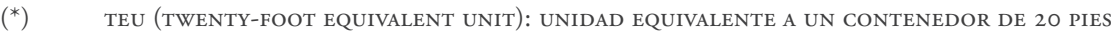

TABLA 2 | Carga contenerizada en los principales puertos mexicanos por litoral, 1988-2017 (participación porcentual)

FUENTE: ELABORACIÓN PROPIA CON BASE EN DATOS DE LA COORDINACIÓN GENERAL DE PUERTOS Y MARINA MERCANTE, MÉXICO

Es importante señalar que los dos puertos más importantes del Pacífico mexicano han avanzado notablemente en el ranking de movimiento de contenedores (medidos en TEU) de Latinoamérica y el Caribe que elabora la Cepal (2018) en su Perfil Marítimo y Logístico y en el informe de la actividad portuaria de América Latina y el Caribe 2018 (Cepal, 2019). Efectivamente, entre 2009 y 2018, Manzanillo pasó del noveno al tercer lugar, de un total de 118 puertos censados, quedando solo detrás del complejo portuario de Colón (Panamá), y de Santos (Brasil). Por su parte, Lázaro Cárdenas avanzó del $19^{\circ}$ al $14^{\circ}$ lugar en el mismo periodo de análisis.

Ahora bien, estos datos no explican la forma en que concentran carga los puertos nacionales, ni sus posibilidades de adquirir mayor relevancia en el concierto internacional; por lo tanto, es necesario incluir elementos de análisis geoeconómico adicionales, como los presentados a continuación.

Criterios 3 y 4. Ámbito territorial de captación de carga y desarrollo de corredores multimodales en puertos mexicanos

Tradicionalmente los puertos obtenían la totalidad de la carga de su región contigua; es decir, los flujos de mercancías eran atraídos o generados mayoritariamente por las localidades y centros urbanos cercanos al puerto. La zona de influencia territorial o hinterland estaba muy acotada por la cercanía física, debido a la escasa eficiencia operativa de los puertos, a las barreras regulatorias y a las dificultades de acceso del transporte terrestre. En este sentido, los expertos en temas portuarios de Unctad (1992) decían que los puertos latinoamericanos tenían hinterlands cautivos, puesto que estas limitaciones en la accesibilidad y el manejo operativo constituían trabas 
muy costosas para que un puerto compitiera por el mercado ubicado dentro de la acotada zona de influencia de otro puerto.

Por el contrario, con el desarrollo de las redes y corredores multimodales y la superación de trabas legales, administrativas y operativas, el ámbito territorial para atraer o generar carga se amplió notablemente. Asimismo, los hinterlands cautivos se rompieron a favor de un hinterland común que puede ser disputado y compartido por varios puertos simultáneamente, siempre y cuando la integración de los modos de transporte lo permita. Por ejemplo, los puertos estadounidenses del Pacífico y del Atlántico han expandido notablemente su hinterland gracias al desarrollo de los sistemas de transporte intermodal. Ahora incluso disputan la zona de influencia de los puertos mexicanos y canadienses. Por eso, en la actualidad, una de las principales formas para concentrar carga y transformar a un puerto en hub regional o global es ampliando el hinterland mediante la integración multimodal.

Ahora bien, para conocer el potencial de los puertos mexicanos y las probabilidades de insertarse y escalar posiciones dentro de la red global de puertos es preciso, en cada caso particular, analizar el ámbito espacial desde el cual obtienen su carga. Aquellos que mantienen como ámbito espacial de influencia su hinterland tradicional difícilmente ascenderán en la jerarquía de la red global; en cambio, aquellos que amplíen su zona de influencia territorial y/o incorporen actividades de transbordo podrán concentrar carga y alcanzar posiciones más sólidas en la red.

Por lo pronto, es necesario señalar que la mayor parte de los puertos nacionales obtienen su carga del hinterland tradicional, comprendido sobre todo por el estado o provincia de pertenencia y los aledaños. Aquí la cercanía y la continuidad geográfica mantienen un papel preponderante, y disminuyen las posibilidades de concentrar carga.

Efectivamente, en tales puertos los flujos tienden a ser poco densos y las redes o conexiones intermodales alcanzan un escaso desarrollo, debido a la carencia de una efectiva articulación territorial. Los agentes ofrecen servicios tradicionales de carga, descarga y almacenamiento de mercancías, así como de avituallamiento de embarcaciones. En estas circunstancias es notable la carencia de servicios e infraestructura especializada y la escasa participación del modo ferroviario en la distribución de carga (tabla 3).

En contraparte, pocos puertos obtienen la carga de un hinterland ampliado, compuesto por diversas ciudades y estados, en los cuales la cercanía física no es tan relevante. Se trata de una estructura de vinculación multirregional basada en redes multimodales que permite al puerto concentrar elevados volúmenes de carga. Destacan al respecto los puertos de Manzanillo y Lázaro Cárdenas, en el Pacífico, y de Veracruz y Altamira en el golfo de México, como se ha dicho. En ellos las conexiones se han ampliado rápidamente, propiciando la consolidación de corredores a partir de trenes de doble estiba y contenedores de mayor densidad expedidos hacia regiones dinámicas del interior del país, como El Bajío, la megalópolis del Valle de México y las zonas productoras del noreste y la frontera norte (figura 4). 


\begin{tabular}{|l|l|l|l|}
\hline \multicolumn{1}{|c|}{ ÁMBITO } & \multicolumn{1}{|c|}{$\begin{array}{c}\text { COBERTURA } \\
\text { ESPACIAL }\end{array}$} & \multicolumn{1}{|c|}{ CONEXIÓN INTERMODAL } & \multicolumn{1}{c|}{ PUERTOS } \\
\hline $\begin{array}{l}\text { Hinterland } \\
\text { tradicional }\end{array}$ & $\begin{array}{l}\text { Limitada } \\
\text { Zonas contiguas al } \\
\text { puerto }\end{array}$ & $\begin{array}{l}\text { Escasa integración modal } \\
\text { Flujos débiles } \\
\text { Escasa participación del ferrocarril } \\
\text { Carencia de servicios e infraestructura } \\
\text { especializada } \\
\text { Oferta de servicios tradicionales }\end{array}$ & $\begin{array}{l}\text { Ensenada } \\
\text { Guaymas } \\
\text { Mazatlán } \\
\text { Salina Cruz } \\
\text { Puerto Chiapas } \\
\text { Tampico } \\
\text { Tuxpan } \\
\text { Coatzacoalcos } \\
\text { Puerto Progreso } \\
\text { Puerto Morelos }\end{array}$ \\
\hline $\begin{array}{l}\text { Hinterland } \\
\text { ampliado }\end{array}$ & $\begin{array}{l}\text { Amplia } \\
\text { Multirregional }\end{array}$ & $\begin{array}{l}\text { Infraestructura y servicios especializados } \\
\text { Terminales intermodales } \\
\text { Tesarrollo de corredores multimodales } \\
\text { Orenes de doble estiba } \\
\text { Operadores de transporte multimodal }\end{array}$ & $\begin{array}{l}\text { Manzanillo } \\
\text { Altamira } \\
\text { Veracruz } \\
\text { Lázaro Cárdenas }\end{array}$ \\
\hline $\begin{array}{l}\text { Transbordo } \\
\text { marítimo }\end{array}$ & $\begin{array}{l}\text { Amplia } \\
\text { Nacional } \\
\text { Subcontinental }\end{array}$ & $\begin{array}{l}\text { Fuertes conexiones marítimas } \\
\text { Nodo de enlace entre rutas directas e indirec- } \\
\text { tas } \\
\text { Optimización de maniobras portuarias }\end{array}$ & $\begin{array}{l}\text { Manzanillo } \\
\text { Lázaro Cárdenas }\end{array}$ \\
\hline
\end{tabular}

TABLA 3 | Ámbito espacial de obtención de carga contenerizada en los puertos mexicanos

FUENTE: ELABORACIÓN PROPIA

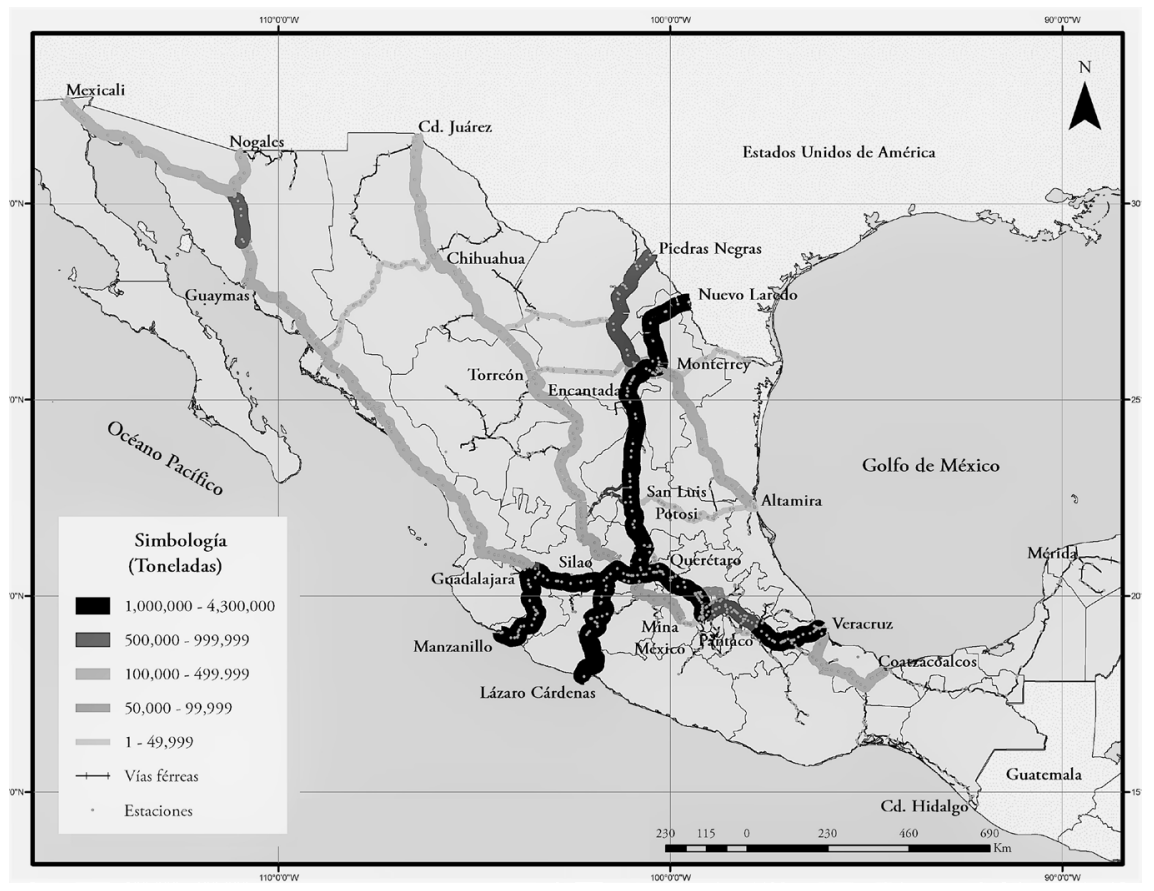

Figura 4 | Principales corredores multimodales en México, 2016 (Ton. de carga en contenedores movida por ferrocarril)

FUENTE: INSTITUTO MEXICANO DEL TRANSPORTE CON DATOS DE LA SECRETARÍA DE COMUNICACIONES Y TRANSPORTES (SCT), MÉXICO. 
En los últimos años, es evidente que la concurrencia de los actores principales en la formación de las redes multimodales ha propiciado el desarrollo de nuevas terminales especializadas con mayor contenido tecnológico, así como la integración de servicios "puerta a puerta" a través de servicios ferroviarios de doble estiba (figura 5), enlazadas a terminales interiores e inclusive a nodos logísticos de la frontera norte, donde se conectan con la red estadounidense.

Al respecto, el puerto de Lázaro Cárdenas, en Michoacán, ha avanzado en la planeación y desarrollo de un corredor multimodal que lo convertirá eventualmente en un nodo de articulación de flujos entre el Lejano Oriente y el centro-este de los Estados Unidos. Por su parte, Manzanillo trabaja también en una posible conexión con la frontera norte, a través de Piedras Negras (Coahuila), o de Nuevo Laredo (Tamaulipas). Aquí, como en el caso de Lázaro Cárdenas, la concurrencia de diversos actores locales y globales para articular el puerto a través del desarrollo de un corredor multimodal nacional e internacional es una condición ineludible para la inserción del puerto en la red global.

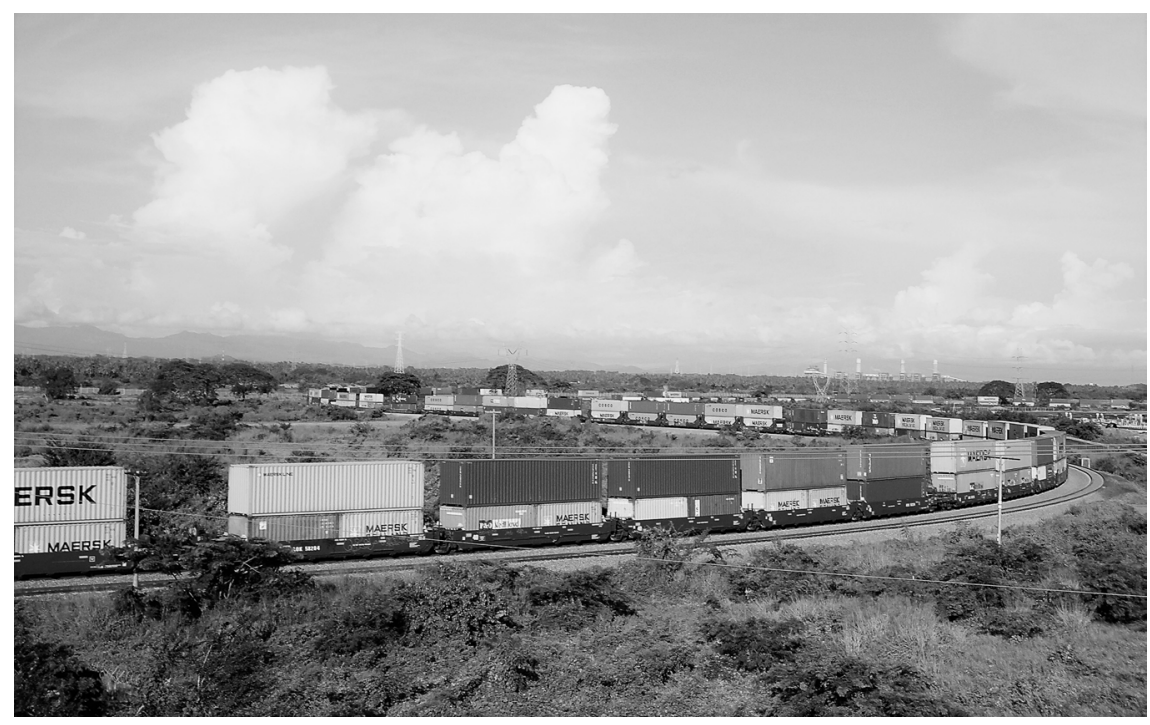

FIGURA 5 | Tren de doble estiba de contenedores en el puerto de Lázaro Cárdenas. México, 2017

FUENTE: FOTOGRAFÍA DEL AUTOR

El papel de los actores en la creación de redes multimodales articuladas a los puertos Dentro de la nueva articulación multirregional que han desarrollado puertos como Manzanillo y Lázaro Cárdenas en el Pacífico mexicano, destacan, por los impactos en la reestructuración territorial, aquellas establecidas con regiones interiores donde predominan emplazamientos de empresas globales, cuyas plantas trabajan con sistemas de producción flexible (Justo a Tiempo, Kan-Ban, etcétera). 
La articulación con estas zonas o fragmentos territoriales, caracterizados en México por la presencia de plantas de las ramas automotriz, electrónica y química principalmente, genera una dinámica económica y territorial singular. Aquí no solo se establecen lazos de conexión entre el puerto y zonas interiores distantes (como la Ciudad de México, las ciudades El Bajío, Aguascalientes, Guadalajara y Monterrey, entre otras), sino que también se genera una fuerte integración productiva entre tales fragmentos territoriales. El puerto entra a formar parte del proceso de producción-circulación de estas empresas y tiene labores concretas. En efecto, se trata de flujos internacionales de bienes intermedios intrafirmas o intrarrama, es decir, de productos que circulan al interior de un proceso productivo externalizado.

Como estas redes son sumamente exigentes debido a que trabajan con sistemas de producción Justo a Tiempo, es decir, con inventarios mínimos y un nivel de aprovisionamiento de insumos que se ajusta a las fluctuaciones de la demanda, requieren certeza en sus envíos; por lo tanto, establecen fuertes presiones sobre la operación portuaria, sobre las navieras, sobre las empresas de transporte multimodal y sobre diversos agentes involucrados en el proceso. En este sentido, tienden a modificar la función del puerto, de sus enlaces y de la conectividad interespacial con los fragmentos territoriales interiores donde se localizan las plantas. Lo cierto es que el sistema flexible Justo a Tiempo, utilizado a larga distancia, implica un desdoblamiento muy amplio del proceso de producción-circulación sobre el territorio.

En el caso de Manzanillo, por ejemplo, la terminal portuaria se ha integrado en el proceso productivo de plantas automotrices como Nissan y sus proveedores, localizados en Aguascalientes, a más de $550 \mathrm{~km}$ del litoral del Pacífico, y en otras ciudades del Bajío y el centro del país, localizadas incluso a más de $900 \mathrm{~km}$, como es el caso de la Nissan de Cuernavaca. En estos casos, el puerto funciona como gestor, administrador y distribuidor de inventarios en los tiempos y los ritmos demandados por la red productiva internacionalizada de la empresa automotriz en cuestión. Los contenedores que llegan al puerto tienen diferentes prioridades de entrega. Aquellos de mayor prioridad deben ser entregados en las plantas del interior (en Aguascalientes, principalmente) en menos de 24 horas, desde el momento en que son descargados del barco en Manzanillo. Los de segunda prioridad tienen que colocarse en fábrica en menos de 48 horas, y así sucesivamente hasta llegar a la quinta prioridad.

Los empleados de la empresa automotriz y los agentes de transporte multimodal, subcontratados por la primera, realizan la gestión de estos flujos, observando un control férreo sobre los tiempos de entrega para no parar la línea de producción o para no acumular costosos inventarios en planta. Este estricto control sobre el proceso de producción-circulación deviene en un exhaustivo control sobre el territorio, o al menos sobre fragmentos específicos de él. En consecuencia, se define una nueva forma de interacción espacio-temporal, debido a la posibilidad de desarrollar y coordinar actividades productivas interconectadas en tiempo real, entre fragmentos territoriales ampliamente distantes (Martner, 2001).

Desde luego, este control y peculiar forma de articulación y conectividad interespacial supone acciones tangibles sobre el territorio para mejorar la integración física y productiva. La construcción de autopistas de cuatro carriles, las redes de 
ferrocarril de doble estiba de contenedores y la introducción de modernos sistemas de comunicación e información son obras de infraestructura de importante envergadura. En tal condición, implican modificaciones de la estructura territorial de determinados fragmentos espaciales, además de reforzar los vínculos del puerto con regiones interiores de gran dinamismo y adaptabilidad para insertarse en los procesos productivos globales.

Más significativo aún es el hecho de que estas modificaciones tienen un sentido cualitativamente diferente, dado que responden a otra racionalidad en la estructuración del territorio. Efectivamente, no se trata de la acumulación de obras de infraestructura, sino de la creación de objetos destinados - como diría Santos- a favorecer la fluidez. En el mismo sentido, Castells (2006) denomina a estos objetos como soportes materiales de la simultaneidad, dado que permiten coordinar, incluso en tiempo real, actividades ampliamente separadas en el espacio. Para este autor, tales soportes materiales, que posibilitan la fragmentación y discontinuidad física de los vínculos territoriales, son característicos de la conformación del espacio de flujos de la globalización.

En términos de Brenner (2013), se podría decir que vastos territorios, incluyendo corredores y rutas transoceánicas, se han transformado en espacios estratégicos de la urbanización extendida a través de diversos tipos de infraestructuras especializadas, entre las que se incluyen tanto las vías navegables como los soportes materiales, previamente mencionados, que estimulan la circulación y la fluidez en un espacio global y urbanización planetaria crecientemente interconectada.

Los puertos de Manzanillo y Lázaro Cárdenas son, nuevamente, un buen ejemplo de la conformación del territorio de redes, apoyados en el desarrollo de soportes peculiares para crear fluidez, tales como las terminales multimodales y plataformas logísticas (Antún, 1995), que generan una suerte de acercamiento de fragmentos territoriales distantes. Así, a través de estos soportes materiales integrados en tiempo y espacio, es factible programar los requerimientos y envíos de insumos de acuerdo con los inventarios y ritmos de producción de las plantas en cuestión.

En este caso, los soportes en referencia son, por ejemplo, las terminales multimodales de contenedores de Manzanillo y Aguascalientes. A la construcción de la terminal de contenedores de Manzanillo, siguió la de una instalación similar en un nodo regional interior: la terminal de contenedores de Aguascalientes, ubicada a un costado de la planta de Nissan. Tales terminales han sido articuladas espacial y temporalmente por un innovador sistema de comunicación, el EDI (Intercambio Electrónico de Datos), manejado por los operadores logísticos y de transporte multimodal (TMM, APL Logistics) y por las plantas de la rama automotriz ubicada en la región. Este sistema permite conocer, en tiempo real, los requerimientos de bienes intermedios para preparar anticipadamente la logística de aprovisionamiento y distribución. Además, la integración espacio-temporal entre el puerto de Manzanillo y los fragmentos territoriales interiores ha sido reforzada por modernas autopistas y por la introducción del ferrocarril de doble estiba. Por lo tanto, la consolidación del territorio de redes no se produce solo por la intensificación de flujos, sino también por la de "fijos", en el sentido de Santos (2000), representados en este caso por los objetos necesarios para crear fluidez. 
Las instalaciones similares para el movimiento de contenedores desde los puertos de Manzanillo y Lázaro Cárdenas hacia las regiones del interior tienden a multiplicarse. En efecto, en ciudades del occidente, Bajío, norte y centro, se han creado terminales intermodales interiores para el manejo de contenedores. Desde luego, ello responde a la localización de nuevas plantas de empresas globales, como General Motors, en Silao y Saltillo; Daewoo, Samsung y Mabe, en Querétaro; Honda en Celaya y Guadalajara; Mazda en Salamanca, etcétera. Lo cierto es que tal situación está reforzando la articulación fragmentada, multirregional y multinodal de Manzanillo y Lázaro Cárdenas.

Ahora bien, el desarrollo de estos objetos o soportes materiales no se explica sin la presión de agentes sociales importantes, como las propias empresas aludidas, los gobiernos estatales y los agentes de transporte multimodal. Y es que la creación de objetos para apoyar la fluidez no es un evento distribuido de manera homogénea en el territorio, cuya función principal sea buscar equilibrios regionales. Por el contrario, pasa necesariamente por las presiones de grupos económicos y por las decisiones del poder político.

En este sentido, Santos (2000) advierte:

La producción de fluidez es una iniciativa conjunta del poder público y del sector privado. Cabe al Estado (...) proporcionar al territorio los microsistemas técnicos sin los cuales las demás técnicas no se hacen efectivas. Las empresas, aisladamente o asociadas, establecen las redes privadas, cuya geografía y funcionalización corresponden a su propio interés mercantil. Es por donde circulan -no raras veces de forma exclusiva- las informaciones (...) [los bienes] (...), los datos especializados y las órdenes que estructuran la producción. (p. 233)

Así, agrega, "la existencia de las redes es inseparable de la cuestión del poder. La división territorial del trabajo resultante atribuye a algunos actores un papel privilegiado en la organización del espacio" (p. 229).

En definitiva, la producción de fluidez, dentro de la economía-mundo capitalista, es selectiva. Los actores escogen un puerto que, por sus aptitudes, se convierta en un nodo de articulación de redes, capaz de desplegarse sobre fragmentos territoriales específicos y, a la vez, generar fluidez. Sin embargo, no debe olvidarse que la emergencia de esta nueva forma de organización espacial de los sistemas globales de producción-circulación excluye a gran cantidad de puertos y espacios litorales no integrados en red.

\section{Reflexiones finales}

El análisis previo permite esbozar de manera preliminar los siguientes hechos y tendencias relevantes en torno al papel de la conectividad interespacial y la articulación modal, logística y territorial en el desarrollo de los puertos mexicanos.

La conectividad es un elemento clave para mejorar la posición competitiva de los puertos y es condición sine qua non para la formación y consolidación de redes multimodales vinculadas a puertos concentradores. Efectivamente, los puertos de este tipo requieren concentrar carga expandiendo y diversificando su hinterland, 
y esto es posible mediante una tersa articulación modal y logística que permita el flujo continuo de suministro de las cadenas de producción-circulación globalizadas.

Sin embargo, no todos los puertos mexicanos tienen posibilidades de transformarse en hubs, aunque existen ventajas geográficas que podrían ser explotadas por más de uno para concentrar y redistribuir carga internacional. El hecho de que los puertos mexicanos del Pacífico se encuentren prácticamente sobre el eje de intersección de los corredores este-oeste y las rutas norte-sur, los habilita potencialmente para desarrollar actividades de transbordo de contenedores entre Asia y Latinoamérica, además de la concentración de carga que puedan obtener de sus zonas de influencia territorial. En ambas situaciones, sin embargo, habría que alcanzar una mayor eficiencia mediante la consolidación de los corredores intermodales.

En este momento, los puertos del Pacífico mexicano con mayores posibilidades de transformarse en concentradores regionales son Manzanillo y Lázaro Cárdenas. Varios elementos apoyan esta afirmación. Además de la localización geográfica de ambos, se observa una creciente presencia de actores locales, regionales y globales dedicados a crear fluidez y a acelerar la circulación física de las mercancías; entre ellos, operadores logísticos locales, nacionales y extranjeros; agentes aduanales, operadores multimodales, consorcios de navieras globales con sus divisiones logísticas, transportistas ferroviarios y carreteros, zonas de actividades logísticas aledañas al puerto para darle servicio a la carga y al transporte, operadores de terminales especializadas nacionales e internacionales, operadores locales y nacionales de terminales remotas, así como actores del sector público y de organizaciones sociales (tanto de trabajadores portuarios, como de temas relativos a la ciudad y el medioambiente).

En este contexto, ambos puertos han articulado sendos corredores intermodales de doble estiba de contenedores hacia el occidente, norte y centro del país, y a la vez comienzan a recibir enormes embarcaciones; los mayores buques de contenedores registrados en las costas nacionales (superiores a los 13 mil TEUs), lo cual ha permitido concentrar y distribuir volúmenes crecientes de carga en el litoral del Pacífico.

La combinación de los elementos señalados previamente les otorga a los puertos Manzanillo y Lázaro Cárdenas la posibilidad de desarrollar progresivamente actividades como centros de transbordo regional-continental para rutas y líneas alimentadoras de Centro y Sudamérica, que requieren una mayor gama de conexiones con Asia y Europa; además pueden ofrecer servicios a un mayor número de cadenas de producción-circulación que localizan fases de sus procesos en diversas regiones de México.

Ahora bien, el ascenso de Manzanillo y Lázaro Cárdenas en la jerarquía de la red global de puertos y transporte multimodal no está asegurada. Dependerá tanto del contexto de competencia internacional como de las políticas del sector público y las acciones de los actores, privado y social, vinculados al desarrollo portuario. No obstante, la potencialidad de estos puertos obliga a incorporar, dentro de una visión integral, los elementos de planeación portuaria, urbana y regional de largo plazo, para responder adecuadamente a las demandas no solo económicas, sino también sociales, regionales y urbanas que implica tal jerarquía portuaria.

No se trata únicamente de determinar de manera anticipada zonas de reserva para nuevas terminales de contenedores. También es necesario prever las conexiones con 
los sistemas de transporte terrestre, la infraestructura de acceso y salida de la carga, las zonas de reserva para el desarrollo de terminales intermodales y plataformas logísticas de consolidación de carga y distribución; y, en general, el desarrollo de la ciudad portuaria en cuanto a la aceleración de la circulación y la fluidez de las cadenas de suministro, pero también a la mejora de las condiciones de vida de sus habitantes.

Por su parte, el potencial de los principales puertos del golfo de México (Veracruz y Altamira) reside más en su consolidación como concentradores nacionales, que en sus aspiraciones de convertirse en hubs regionales de transbordo continental. Para ello, eso sí, requieren consolidar su hinterland nacional a través de una sensible mejora de sus conexiones multimodales hacia ciudades medias y grandes del centro, el Bajío y el sureste del país; conexiones basadas sobre todo en el desarrollo de servicios de doble estiba de contenedores así como en la consolidación de carga en centros de distribución, adelantos que permitan un flujo continuo y ágil de las cadenas de suministro entre los puertos y las zonas del interior.

En definitiva, la formación de redes articuladas a puertos hub supone la formulación de una concepción estratégica con elementos de planeación de largo plazo, que sobrepase el ámbito de recinto portuario e involucre crecientemente al antepuerto y sus actores, a la ciudad portuaria y a las conexiones con las regiones interiores de producción, distribución y/o consumo.

\section{Referencias bibliográficas}

Antún, J. (1995). Logística: Una visión sistémica. Documento Técnico 14. Sanfandila, Querétaro: Instituto Mexicano del Transporte. https:/imt.mx/archivos/Publicaciones/ DocumentoTecnico/dt14.pdf

Braudel, F. 1985). El Mediterráneo. El espacio y la historia. Colección Popular 431. Primera reimpresión. México, DF: Fondo de Cultura Económica.

Brenner, N. (2013). Tesis sobre la urbanización planetaria. Nueva Sociedad, 243, 38-66. http:// www.nuso.org/upload/articulos/3915_1.pdf

Burkhalter, L. (1999). Privatización portuaria: bases, alternativas y consecuencias. Santiago: Naciones Unidas, Comisión Económica para América Latina y el Caribe (Cepal). https://repositorio.cepal.org/bitstream/handle/11362/2205/1/S9910045_es.pdf

Castells, M. (2006) La sociedad red (2a ed.). Madrid: Alianza Editorial.

Comisión Económica para América Latina y el Caribe (Cepal). (2018). Perfil marítimo y logístico de América Latina y el Caribe. Santiago: Autor. http://perfil.cepal.org/l/es/ portmovements_classic.html

Comisión Económica para América Latina y el Caribe (Cepal) (2019). Informe de la actividad portuaria de América Latina y el Caribe 2018. Santiago: Autor. https://www.cepal.org/ es/notas/informe-la-actividad-portuaria-america-latina-caribe-2018

Coriat, B. (1992). Pensar al revés. México, DF: Siglo xxi Editores. 
De Mattos, C. (2016). Financiarización, valorización inmobiliaria del capital y mercantilización de la metamorfosis urbana. Sociologias, 18(42), 24-52. http://dx.doi. org/10.1590/15174522-018004202

Dollfus, O. (2007). La mondialisation. Paris: Presses de Sciences Po.

Fossey, J. (1997). Relay Gold. Containerisation International, 30(6), 10-14.

Hiernaux, D. (1993). Globalización, integración y nuevas dimensiones territoriales: Una aproximación conceptual. Ponencia presentada en el Seminario Internacional Integración y Democratización en América Latina: El Camino Recorrido, Universidad Autónoma Metropolitana, México, DF, 5 al 16 de julio de 1993. Mimeografiado. [Versión digitalizada del artículo según publicado en revista Diseño y Sociedad (México, DF), 1996/Primavera, n. ${ }^{\circ}$ 6, pp. 40-49, en https://bit.ly/2pOxBUo]

Hoffmann, J. (2000). El potencial de los puertos pivotes en la costa del Pacífico sudamericano. Revista de la CEPAL, 71, 121-143. https://www.cepal.org/es/publicaciones/12214potencial-puertos-pivotes-la-costa-pacifico-sudamericano

Martner, C. (2001). Modelos de desarrollo y articulación regional del puerto de Manzanillo. Revista Argumentos, 39, 45-69. http://bidi.xoc.uam.mx/MostrarPDF.php

Martner, C. (2002). Puertos pivotes en México: Límites y posibilidades. Revista de la CEPAL, 76, 123-141. https://repositorio.cepal.org/handle/11362/10805

Martner, C. (2008) Transporte multimodal y globalización en México. México, DF: Editorial Trillas.

Martner, C. (2010). Puertos, espacio y globalización: el desarrollo de hubs en México. Convergencia, 17(52), 319-360. https://convergencia.uaemex.mx/article/view/1190

Ojeda, J. (2000). La situación portuaria en México: los puertos ganadores y los puertos perdedores (1988-1998). Quivera. Revista de Estudios Territoriales, 2(4), 21-36. https:// quivera.uaemex.mx/article/view/10776

O’Kelly, M. (1998). A geographer's analysis of hub-and-spoke networks. Journal of Transport Geography, 6(3), 171-186. http://dx.doi.org/10.1016/S0966-6923(98)00010-6

Santos, M. (2000). La naturaleza del espacio. Barcelona: Ariel Geografía.

United Nations Conference on Trade and Development (Unctad) (1992). La comercialización del puerto y las perspectivas del puerto de tercera generación. Ginebra: Autor, Comisión del Transporte Marítimo.

Veltz, P. (1999) Mundialización, ciudades y territorios, la economía de archipiélago. Barcelona: Ariel Geografía.

Veltz, P. (2014) Mondialisation, villes et territoires: Une économie d'archipel (2. ${ }^{\mathrm{èm}}$ éd.). Paris: Presses Universitaires de France (PUF), Quadrige.

Wallerstein, I. (1996). Después del liberalismo. México, DF: Siglo xxi Editores.

Yocelevzky, R (1999). La relevancia de las contribuciones de Immanuel Wallerstein para las ciencias sociales latinoamericanas. En F. Baca \& B. Cisneros (eds.), Los intelectuales $y$ los dilemas políticos en el siglo XX. Tomo I. México, DF: Universidad Autónoma Metropolitana-Xochimilco.

Zohil, J. \& Prijon, M. (1999). The MED rule: The interdependence of container throughput and transhipment volumes in the Mediterranean ports. Maritime Policy \& Management, 26(2), 175-193. London: Taylor \& Francis. https://doi. org/10.1080/030888399286998 